\title{
Student heterogeneity and leadership training: designing project management pedagogy for maximum learning impact
}

Mona N. Shah National Institute of Construction Management and Research, India

Niranjan S Janardhanan, Indian School of Business, India

"Leaders who keep learning may be the ultimate source of sustainable competitive advantage"

- Fulmer et al (2000)

\begin{abstract}
In today's organisations, project managers' responsibilities go far beyond managing projects within the triple constraints of cost, time and quality (Crawford 2005). They are increasingly being looked upon as drivers of strategic development of their organisations. This transformation in the role of a project manager calls for developing additional competencies such as business analysis and strategic leadership. The Project Management Institute emphasises a focus on these skills for project managers worldwide. Owing to the country's fast pace of growth and the challenges that arise thereof, Indian companies and educational institutions are also fast realising the importance of holistic development of project managers.

Recent research underscores the induction of soft skills and leadership capabilities in project management education. This has led to several studies in the international context that examine student experiences while attending courses in project management. A prominent characteristic that the literature has not dealt with in sufficient detail is the potential impact of prior work experience on students' learning capabilities during the course. Since most Indian schools do not specify prior work experience as an admission requirement, cohorts usually comprise a mix of students with and without prior work experience. Hence, to analyse if pedagogy is effective, we must consider overall student experience and, in addition, whether and how the students' heterogeneity in the form of their past work experience impacts their experience during the course.
\end{abstract}

The objective of this study is to answer two questions: (1) is there a significant difference in perceptions of leadership aspects of project management between experienced and inexperienced students? (2) How can we design project management pedagogy to cater to this heterogeneity and yet provide superior student experience?

Keywords: project management; leadership skills; pedagogy; work experience

\section{Introduction}

Amid increasing complexity and uncertainty in the global business landscape, what often differentiates successful organisations is their ability to adapt to change. Often, companies equipped with the best capabilities and operating in favourable environments still fail due to a lack of clarity among their employees about their role in the organisation. Identifying core competencies for each role in a company leads to the creation of competency frameworks, which in turn help the managers develop these competencies to enable effective performance (Cheng, Dainty \& Moore 2005). Pierce (1994) proposed two categories of competencies, namely key job- 
related task competencies based on deliverable outputs and personal characteristics based on behavioural competencies required for the role. Cheng and colleagues (2003) argued that in addition to technical competence, managers need to develop the "maturity" to lead organisations in dynamic business environments.

Over the past couple of decades, researchers and practitioners have advocated various competencies for project managers based on industry and context. (Cheng, Dainty \& Moore 2005; Crawford 2005; Thomas \& Mengel 2008). Thomas and Mengel (2008) suggest that project management education needs to evolve from mere transfer of know-how to development of the ability to manage under chaos and complexity. Dainty, Cheng and Moore's study (2003) on construction managers yielded the following factors as the key characteristics: team building; leadership; decision making; mutuality and approachability; honesty and integrity; communication; learning and application; self-motivation; and external relations.

As part of a major debate since 2006 about a revamp in the global outlook towards project management, one of the key factors that came about is project management education (Ojiako, et al 2011; Cicmil et al 2006; Winter et al 2006). More specifically, there is now a more sharp focus on the softer aspects of project management (Pollack 2007). Ojiako et al (2011) suggested that a one-size-fits-all approach to teaching project management would no longer hold true owing to the turbulent and dynamic nature of the role of the project manager. There is also an emphasis on the necessity for project managers to be creative and innovative (Kolltveit et al 2007; Ojiako et al 2008). They conclude that transferable skills are extremely important in project management education. Patanukul et al (2007) stress the importance of interpersonal skills more than technical knowledge.

Our study is in response to the recent shift in focus of project management researchers, educators and practitioners towards developing new and innovative educational techniques with an emphasis on integrating theory and practice (Wren, Halbesleben \& Buckley 2007), enabling project managers to develop transferrable skills (Ojiako et al 2011) and manage projects under complex and chaotic situations (Thomas \& Mengel 2008).

\section{Management pedagogy}

Wren and colleagues have undertaken a comprehensive longitudinal study on the theoryapplication balance in management pedagogy at three time-points over a period of three and a half decades (Wren, Atherton \& Michaelsen 1980; Wren, Buckley \& Michaelsen 1994; Wren et al 2007;). According to the results of their latest study (2007), the application focus has increased from the 1980s to the 2000s for courses such as production/operations management (significant at the $\mathrm{p}<0.05$ level) and organisational behaviour $(\mathrm{p}<0.01)$ despite all other courses moving towards a higher theory focus. Although their primary emphasis was on striking the theoryapplication balance in management education, one of the key results was the transformation of pedagogical techniques used over the three time periods. The most significant changes have been in "experiential exercises" and "experience of students", both significant at the $p<0.01$ level. This result clearly shows the importance of relating theories taught in the classroom to practical experiences through effective pedagogy. 
Researchers have explored various pedagogical techniques to effectively achieve the balance between theoretical and practical knowledge, namely: active learning (Heriot et al 2008; Raelin 2006); problem-based learning (Qi \& Gu 2011; Usry et al 2009); whole-person learning (Hoover et al 2010); sustainability-oriented learning (Kashyap et al 2006; Shrivastava 2010); projectoriented learning (Doppelt 2003; Qi \& Gu 2011); experiential learning (McCarthy \& McCarthy 2006); and practical wisdom-oriented learning (Gorman 2011). From a learning theory perspective, most of these techniques derive from inductive learning (Prince \& Felder 2006).

\section{Impact of heterogeneity on inductive learning}

Inductive learning involves a pull-based (Gorman 2011) rather than a push-based approach. When students are provided theories, examples and facts, it is often a push-based approach. Gorman shows that an inductive approach is more effective, since it involves understanding real problems from nature and developing the skills to solve them. These real problems could be from observations, projects undertaken during the course of the program, or past work experiences. According to Gorman, college graduates find it difficult to understand what they have learnt in college, if they do not implement it. The advantage of graduates returning to academic courses after a few years in the work force is that they need not wait till they start working to implement concepts they have learnt. They can readily relate concepts taught in class to what they have experienced in the corporate world. This puts them at a definite advantage in comparison with their inexperienced counterparts in the process of learning.

Ojiako and colleagues (2011) suggest that it is important to understand student experiences during the course and customise the course to their expectations based on their feedback. In their study, after examining student experiences in project management pedagogy, they recommend that students be viewed as customers of education. Ojiako et al checked for differences in perceptions between respondents based on their sex, academic experience and related work experience and found that there are no differences in perceptions across these categories. More often than not, students may not necessarily have experience in the exact same domain as that of their projects. However, the fact that they have any work experience at all would suffice for them to be able to relate what they learn to what they may have studied.

In Qi \& Gu's latest paper (2011) on project-oriented education for a project management course at the undergraduate level in Nankai University, China, they discuss student experience during the course of the project, and the knowledge gathered during the course in an equation: Knowledge + Experience $=$ Skill. Although they mention that the "education of experienced and inexperienced individuals requires different styles", they do not specify in detail as to why this could be the case, and how the styles can be made different.

Our paper expands on these ideas by exploring whether and in what aspects the understanding of students differs on the basis of their work experience. In the following sections, we discuss in detail the leadership workshop at the National Institute of Construction Management and Research (NICMAR) and our understanding of student experiences during the course. We then discuss the results of our empirical analysis and provide recommendations on how students belonging to these two categories could be targeted differently for better pedagogical effectiveness in project management. 


\section{The NICMAR leadership workshop}

The leadership workshop is offered as a compulsory requirement for one of NICMAR's postgraduate programs, Real Estate and Urban Infrastructure Management, and is covered substantially in the two other programs, Project Engineering and Management and Advanced Construction Management, as well in the managerial skills workshops and the Organisational Behaviour course.

\section{Objective}

Leadership is essential for the managers in the making. The primary objective of this workshop is to develop key skills in future leaders, namely communication, negotiation, analytical, people and decision-making skills. Through this course, the students learn leadership qualities such as vision, initiative, team building, problem solving, growth and the development of individuals and organisations.

\section{Pedagogy}

This is a unique offering wherein students are provided substantial exposure to the practice of leadership in organisations. The students are exposed to a three-pronged input comprising the following:

1. Invited Speakers: The first category entails talks of around two hours' duration by eminent senior leaders from the private and public sectors and non-government organisations, identified by the instructor with the help of students from the course. These leaders also discuss their "journey of leadership", sharing their personal values, management styles, anecdotes, challenges and beliefs with the students.

2. Active Learning: The second category of learning in the course comprises sessions by the instructors using cases and situations (role-play, etc), to help the students learn the discipline of leadership through active participation.

3. Independent Study Project: Third, students undertake individual projects of their choice, which are vetted by the instructor, over a period of 8-10 weeks that introduces them to the practice of leadership.

\section{Process and assessment}

The workshop is a five-credit course. Class and guest lecture attendance form a small proportion of the grade. For the project, time is allocated to students in their weekly curriculum. Regular follow-up is done through the administrative system to capture student progress and students are counselled by the instructor in case of any difficulties. A project report is required to be submitted at the end of the term. Students are assessed for their performance in the individual project based on the following parameters: (1) proper documentation of progress in the project; (2) photos of the student engaged in the process with the chosen recipients; (3) descriptions regarding the choice of project, persons contacted and interactions had; (4) leadership lessons learned; and (5) a personal interview conducted before the award of final marks. Students are divided into groups of 30-35 and two sessions of two hours and forty minutes per week are assigned in the regular timetable for this activity per group. However, students are free to spend weekends or other convenient slots based on the host project recipients' convenience for this activity.

\section{Student satisfaction}


A feedback form covering instructor effectiveness and course effectiveness is collected from all the students at the end of the course. The workshop received a rating of over $80 \%$ from the two cohorts that had completed the course.

\section{Method and measures}

In addition to the student feedback forms collected immediately after the workshop in both years, the students were provided with a 20 -item questionnaire on aspects they had learnt during the course. This was done during the second-half of the year when the second cohort was still at the institute. The first cohort had already graduated from the program and had just started working. The questionnaire was meant to analyse the student experience during the course. The questionnaire was administered online and the students were contacted via email to complete the questionnaire. ${ }^{1}$ Demographic questions added were about sex, type and length of prior work experience. All questions were coded on a 7-point Likert scale (Likert 1932), where 1 meant "strongly disagree" and 7 meant "strongly agree". The items were based on sources mentioned above such as Ojiako et al (2011) and Thomas and Mengel (2008).

We obtained responses from 112 students, 94 males (84\%) and 17 females (15\%). The average work experience prior to the program was 16 months. There were students who had not worked at all, and the maximum work experience was 8 years. For the sake of comparison of students with and without work experience, a dummy variable "WorkExp10" was created, which took values of ' 0 ' for the 25 students (22\%) with no work experience and ' 1 ' for the remaining 87 students (78\%) with at least 2 months of work experience. To ensure that a small amount of work experience did not make too much of a difference, we repeated the analysis with the dummies taking values of ' 1 ' only for students with at least 6 months and at least a year of work experience. The results obtained were similar.

\section{Analysis}

\section{Overall student experience}

The overall student experience was positive, with a mean score on all parameters of 5.3 on a scale of 7. The top three factors for which the students' experience was the highest were communication skills, flexibility to ideas and managing relationships. See Table 1 for descriptive statistics of all items. Overall leader characteristics received a very high score of 5.6 on 7.

\section{Impact of work experience}

Table 2 shows descriptive statistics for students with and without work experience. A key finding was that the mean experience scores for students with work experience were higher for all the items compared with students without work experience. For students without work experience, the top three learnings they got from the workshop were flexibility to ideas, values and ethics. For the experienced students, the top three learnings were communication skills, managing relationships and flexibility to ideas.

\footnotetext{
${ }^{1}$ The authors would like to express their sincere gratitude to Rohan Desai for his help in administering the questionnaires, and collecting and consolidating the responses.
} 


\begin{tabular}{lccc} 
Items & N & Mean & S.D. \\
\hline Communication skills & 110 & 5.49 & 1.21 \\
Flexibility to ideas & 110 & 5.48 & 1.16 \\
Managing relationships & 110 & 5.40 & 1.20 \\
Decision making under uncertainty & 112 & 5.33 & 1.24 \\
Vision & 112 & 5.31 & 1.15 \\
Values & 111 & 5.30 & 1.12 \\
Gap identification & 112 & 5.29 & 1.12 \\
Attention to detail & 112 & 5.29 & 1.29 \\
Big picture & 111 & 5.25 & 1.23 \\
Deadlock resolution & 112 & 5.25 & 1.20 \\
Complexity & 111 & 5.24 & 1.24 \\
New idea generation & 112 & 5.21 & 1.30 \\
Self awareness & 112 & 5.20 & 1.25 \\
Ethics & 112 & 5.19 & 1.18 \\
Problem solving & 111 & 5.16 & 1.22 \\
Role model & 112 & 5.07 & 1.31 \\
Overall leader characteristics & 110 & 5.57 & 1.14 \\
Course relevance & 110 & 5.15 & 1.49 \\
Course application & 109 & 5.20 & 1.35 \\
Course integration & 111 & 4.86 & 1.44 \\
\hline
\end{tabular}

Table 1. Descriptive statistics - overall

\begin{tabular}{|c|c|c|c|c|c|c|}
\hline \multirow{2}{*}{ Items } & \multicolumn{3}{|c|}{ Without work experience } & \multicolumn{3}{|c|}{ With work experience } \\
\hline & $\mathrm{N}$ & Mean & S.D. & $\mathrm{N}$ & Mean & S.D. \\
\hline Attention to detail & 25 & 4.68 & 1.82 & 87 & 5.46 & 1.04 \\
\hline Big picture & 25 & 4.48 & 1.39 & 86 & 5.48 & 1.09 \\
\hline Communication skills & 24 & 4.63 & 1.44 & 86 & 5.73 & 1.02 \\
\hline Complexity & 24 & 4.58 & 1.41 & 87 & 5.43 & 1.14 \\
\hline Deadlock resolution & 25 & 4.36 & 1.44 & 87 & 5.51 & .99 \\
\hline Decision making under uncertainty & 25 & 4.64 & 1.58 & 87 & 5.53 & 1.05 \\
\hline Ethics & 25 & 4.84 & 1.49 & 87 & 5.29 & 1.07 \\
\hline Flexibility to ideas & 25 & 5.00 & 1.66 & 85 & 5.62 & .93 \\
\hline Gap identification & 25 & 4.64 & 1.38 & 87 & 5.47 & .96 \\
\hline Managing relationships & 25 & 4.56 & 1.64 & 85 & 5.65 & .91 \\
\hline New idea generation & 25 & 4.56 & 1.71 & 87 & 5.40 & 1.09 \\
\hline Problem solving & 25 & 4.40 & 1.35 & 86 & 5.38 & 1.09 \\
\hline Role model & 25 & 4.52 & 1.50 & 87 & 5.23 & 1.21 \\
\hline Self awareness & 25 & 4.48 & 1.64 & 87 & 5.40 & 1.04 \\
\hline Values & 24 & 4.88 & 1.26 & 87 & 5.41 & 1.06 \\
\hline Vision & 25 & 4.80 & 1.38 & 87 & 5.46 & 1.04 \\
\hline Overall leader characteristics & 25 & 5.20 & 1.55 & 85 & 5.68 & .97 \\
\hline Course integration & 25 & 3.92 & 1.63 & 86 & 5.13 & 1.26 \\
\hline Course relevance & 23 & 3.96 & 1.58 & 87 & 5.47 & 1.30 \\
\hline Course application & 24 & 4.21 & 1.74 & 85 & 5.48 & 1.08 \\
\hline
\end{tabular}

Table 2. Descriptive statistics - split by work experience 


\begin{tabular}{lcc}
\hline & \multicolumn{2}{c}{ t-test for Equality } \\
\cline { 2 - 3 } Items & $\mathbf{N}$ & Mean difference \\
\hline Attention to detail & 110 & $.78^{* * *}$ \\
Big picture & 109 & 1.00 \\
Communication skills & 108 & $1.11^{*}$ \\
Complexity & 109 & .84 \\
Deadlock resolution & 110 & $1.15^{* *}$ \\
Decision making under uncertainty & 110 & $.89 *$ \\
Ethics & 110 & .45 \\
Flexibility to ideas & 108 & $.62^{* * *}$ \\
Gap identification & 110 & $.83^{*}$ \\
Managing relationships & 108 & $1.09 * * *$ \\
New idea generation & 110 & $.84 * *$ \\
Problem solving & 109 & .98 \\
Role model & 110 & .71 \\
Self awareness & 110 & $.92^{* * *}$ \\
Values & 109 & .54 \\
Vision & 110 & .66 \\
\hline Overall leader characteristics & 108 & $.48^{* *}$ \\
Course integration & 109 & 1.21 \\
Course relevance & 108 & 1.51 \\
Course application & 107 & $1.27 * * *$ \\
\hline
\end{tabular}

$*_{p}<0.05, * *_{p}<0.01, * * *_{p}<0.001$

Table 3. $t$-test comparison of means between students with and without work experience

Table 3 shows the results of the $t$-test comparison of means between students with and without experience. It shows significant differences in means between the two groups at the $p<0.001$ level for four items; namely, attention to detail, flexibility to ideas, managing relationships and course application. At the $\mathrm{p}<0.01$ level, there are three items; new idea generation, selfawareness and overall leader characteristics. Overall, there is a significant mean difference of $0.83(\mathrm{p}<0.01)$ between the two groups, with students with work experience scoring higher.

\section{Discussion}

This paper answers the call from recent researchers and practitioners (Ojiako et al 2011; Thomas \& Mengel 2008) to develop management pedagogy encompassing both hard and soft aspects of project management. Building leadership competencies of project managers can be done through a careful mix of inductive learning techniques. Our methodology at NICMAR is a unique approach to ensure that students are able to build these capabilities and use them in their jobs after they graduate. Our study was to understand student experiences during the workshop. We found that the overall student experience was very positive. Students benefited most by understanding and learning communication skills, learning to be flexible with new ideas and managing relationships during the course of their independent projects. This tends to suggest that the more practical aspects of leadership should be the focus in leadership pedagogy going forward. 
However, before we make this conclusion about the overall sample, we must understand the differences if any owing to the heterogeneity of our sample. One of the key motivations for conducting this study was to understand whether prior work experience has an impact on student perceptions and learning. The results show three key differences between students with and without prior experience. First, the students with prior experience rated all the characteristics higher in comparison with their inexperienced peers. The $t$-test also shows that course application was rated very highly by students with work experience. This clearly shows evidence and effectiveness of inductive learning, in that experienced students are able to relate what they learn in the classroom to their work experience before the course. Even though our sample contained students with an average work experience of only 16 months, their scores were significantly higher.

Second, for 11 factors, the scores are significantly different between the two groups. Attention to detail, managing relationships and flexibility to ideas were rated significantly higher by experienced students. These factors have an overall high rating possibly owing to the fact that they were ranked significantly higher by experienced students. Third, we studied this contrast of factors important to students based on their work experience. Flexibility to ideas was rated significantly higher by both categories of students. This meant that the workshop, more specifically the independent project, was successful in making students think outside the box and become flexible to new ideas. The other two top factors for experienced students are communication skills and managing relationships. In contrast, the inexperienced students rated values and ethics higher.

The results clearly show a difference in perception and learning between the two categories of students. Experienced students relate better to practical aspects of leadership such as communication and relationships. They are able to understand the importance of these factors by relating back to their experiences in the real world. For inexperienced students, on the other hand, it is more important to understand the values and ethics of good leadership before they enter the workplace. Taking Ojiako's perspective (2011) that students are customers of the teaching experience, pedagogy must be structured suitably to provide these relevant aspects to the students based on which aspects would provide them with the best experience.

The findings also show that having undergone the same course, experienced students feel more satisfied with communication skills and interpersonal skills, or the more practical aspects of leadership, while inexperienced students learnt more about moral aspects of leadership. Hence, it could also be argued that the importance of moral aspects should be stressed more for experienced students since they are able to relate to the practical aspects owing to their past experience.

\section{Conclusion and recommendations}

Incorporating the best aspects of active and inductive learning, NICMAR's leadership workshop ensures that it enriches student experiences irrespective of their level of work experience. The active learning approach through lectures and projects ensures that students are able to implement what they are taught in a real-life project well before they enter the workplace. Students with work experience are able to benefit from inductive learning by relating concepts learnt in the classroom with their past experiences. One of the best methods to help students 
understand the different aspects of leadership is through role-play with active participation from both categories of students. These role-play sessions enable students to bring to the classroom their past experiences and learning through the course and the project. This helps the students to learn from each other. Students with work experience could bring practical aspects of the real world and real challenges faced in project management into the classroom. Our study, like past research (Wren et al 2007), found that the sharing of student experiences is highly effective in its impact on the in-class and course experience of other students.

Our study clearly underscores the overall importance of a hands-on, three-pronged teaching approach to leadership training for maximum impact in project management education. A key learning through this study is that experienced students and inexperienced students learn differently. Structuring leadership training and pedagogy for a mixed audience will have to take this into account since experienced students look for, learn from and are happy to learn different things compared with inexperienced students.

\section{Limitations and future work}

Since this is a preliminary study of a leadership workshop in its early stages of development, it is a simple analysis using single-item measures for all the aspects of leadership tested. Also, owing to the fact that the workshop has been conducted only for the past two years, our sample size was limited to two cohorts of students (from the years 2011 and 2012). Hence, a logical next step would be to focus on the few areas of leadership that were prominent in this study, and delve deeper with multi-item scores for checking reliability on a larger sample of students, once subsequent cohorts have completed the workshop.

An important extension of this study would be to understand what the key and relevant leadership characteristics are according to the industry. Our survey items are purely based on past academic research, most of which were not done in the Indian context (Cheng et al 2005; Ojiako et al 2011; Thomas \& Mengel 2008). Hence, it is important to understand what capabilities and competencies the Indian corporate world is interested in, in their prospective project managers, and to ensure that our pedagogy caters to this requirement in a more objective way, taking into account student heterogeneity in prior work experience.

\section{References}

Cheng, M., Dainty, A.R.J. \& Moore, D.R. 2003, The differing faces of managerial competency in Britain and America', Journal of Management Development, vol. 22, no. 6, 527-537.

Cheng, M., Dainty, A.R.J. \& Moore, D.R. 2005, What makes a good project manager?' Human Resource Management Journal, vol. 15, no. 1, 25-37.

Cicmil, S., Williams, T., Thomas, J. \& Hodgson, D. 2006, Rethinking project management: researching the actuality of projects, International Journal of Project Management, vol. 24, 675-686.

Crawford, L. 2005, Senior management perceptions of project management competence, Journal of Project Management, vol. 23, no. 1, 7-16.

Dainty, A.R.J., Cheng, M. \& Moore, D.R. 2003, Redefining performance measures for construction project managers: an empirical evaluation, Construction Management and Economics, vol. 21, no. 2, 209-218.

Doppelt, Y. 2003, Implementation and assessment of project-based learning in a flexible environment, International Journal of Technology and Design Education, vol. 13, 255-272.

Fulmer, R.M., Gibbs, P.A. \& Goldsmith, M. 2000, Developing leaders: how winning companies keep on winning, Sloan Management Review, vol. 42, no. 1, 49.

Gorman, M.F. 2011, Student reactions to the field consulting capstone course in operations management at the University of Dayton, Interfaces, vol. 41, no. 6, 564-577. 
Heriot, K., Cook, R. G., Jones, R., Simpson, L. 2008, The use of student consulting projects as an active learning pedagogy: a case study in production/operations management course, Decision Sciences Journal of Innovative Education, vol. 6, no. 2, 463-481.

Hoover, J.D., Giambatista, R.C., Sorenson, R.L. \& Bommer, W.H. 2010, Assessing the effectiveness of whole person learning pedagogy in skill acquisition, Academy of Management Learning \& Education, vol. 9, 192203.

Kashyap, R., Mir, R. \& Iyer, E. 2006, Toward a responsive pedagogy: linking social responsibility to firm performance issues in the classroom, Academy of Management Learning \& Education, vol. 5, 366-376.

Kolltveit, B., Karlsen, J. \& Gronhaug, K. 2007, Perspectives on project management, International Journal of Project Management, vol. 25, 3-9.

Likert, R. 1932, A technique for the measurement of attitudes, Archive of Psychology, vol. 22, no. 140, 1-55.

McCarthy, P.R. \& McCarthy, H.M. 2006, When case studies are not enough: integrated experiential learning into business curricula, Journal of Education in Business, vol. 81, no. 4, 201-204.

National Institute of Construction Management and Research 2011, Prospectus of 2 year full time post graduate programme in real estate and urban infrastructure management, NICMAR, http://www.nicmar.ac.in.

Ojiako, G.U., Ashleigh, M., Chipulu, M. \& Maguire, S. 2011, Learning and teaching challenges in project management', International Journal of Project Management, vol. 29, 268-278.

Ojiako, G.U., Johansen, D., Greenwood, D., Edum-Fotwe, F. 2008, Facilitating the development of project managers as reflective and creative practitioners, Working Paper Series: Interdisciplinary Studies in the Built and Virtual Environment, vol. 1, no. 1, 66-73.

Patanukul, P., Milosevic, D. \& Anderson, T. 2007, A decision support model for project manager assignments, IEEE Transactions on Engineering Management, vol. 54, no. 3, 548-564.

Pierce, C. 1994, Executive competencies: research issues, Activities \& Responses', Executive development, vol. 7 , no. $4,18-20$.

Pollack, J. 2007, The changing paradigms of project management', International Journal of Project Management, vol. 25, 266-274.

Prince, M. \& Felder, R. 2006, Inductive teaching and learning methods: definitions, comparisons \& research bases, Journal of Engineering Education, vol. 95, no. 2, 123-138.

Qi, A. \& Gu, J. 2011, Project-oriented education for a project management course at the undergraduate level: experience of pedagogy — a case study from Nankai University of China, Journal of Project, Program \& Portfolio Management, vol. 2, no. 1, 47-66.

Raelin, J. 2006, Does action learning promote collaborative leadership? Academy of Management Learning \& Education, vol. 5, 152-168.

Shrivastava, P. 2010, Pedagogy of passion for sustainability, Academy of Management Learning \& Education, vol. 9, 443-455.

Thomas, J. \& Mengel, T. 2008, Preparing project managers to deal with complexity —advanced project management education, International Journal of Project Management, vol. 26, 304-315.

Usry, M.L., White, M.M. \& Olive, J.J. 2009, International business capstone course - an analysis of success, Journal of Global Business Education, vol. 9, 61-76.

Winter, M., Smith, C., Morris, P. \& Cicmil, S. 2006, Directions for future research in project management: the main findings of a UK government-gunded research network, International Journal of Project Management, vol. $24,638-649$.

Wren, D.A., Atherton, R.M. \& Michaelsen, L.K. 1980, Theory and applications in management pedagogy: an empirical study, Journal of Management, vol. 6, no. 1, 21-31.

Wren, D. A., Buckley, M.R. \& Michaelsen, L.K. 1994, The theory/applications balance in management pedagogy: where do we stand?' Journal of Management, vol. 20, no. 1, 141-157.

Wren, D.A., Halbesleben, J.R.B. \& Buckley, M.R. 2007, The theory-application balance in management pedagogy: a longitudinal update, Academy of Management Learning \& Education, vol. 6, no. 4, 484-492.

\footnotetext{
About the authors

Mona N Shah is a professor at NICMAR's, School of Projects, Real Estate and Infrastructure Management

(SOPRIM). She has published/presented over 33 papers in national and international journals and conferences. Her research, teaching and consulting are in the areas of management and leadership, and sustainable development, applied to the sectors of projects, real estate and infrastructure.

Email: mnshah@nicmar.ac.in
} 
Niranjan S Janardhanan is a research associate in Organisational Behavior at the Indian School of Business. He has co-authored a book chapter in organisational development and has participated in several international conferences, presenting his work on leadership and intragroup conflict. He currently works in the areas of conflict, voice and organisational citizenship behavior. He will be pursuing his $\mathrm{PhD}$ in Management from the University of Texas, Austin.

Email: niranjan.s.janardhanan@gmail.com 